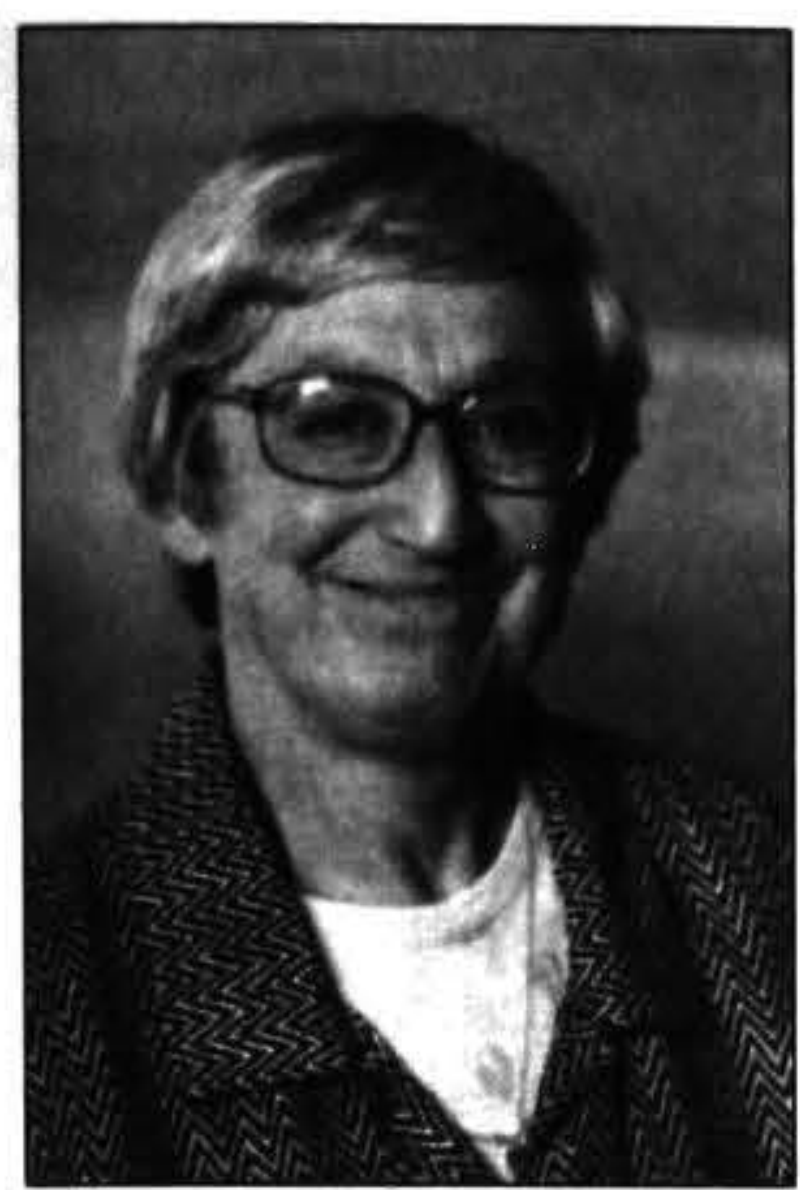

\title{
PAY EQUITY AND EQUAL EMPLOYMENT OPPORTUNITY - DEVELOPMENTS 2004/2006 AND EVALUATION
}

\author{
Prue Hyman \\ Gender and Women's Studies, \\ Victoria University of Wellington
}

\begin{abstract}
My 2004 LEW paper (Hyman, 2006) argued that given the plethora of studies and reports in this area in New Zealand and overseas, the most urgent priority was practical development and piloting of means of implementation of pay and employment equity. There are positive developments, including the establishment and work of the Pay and Employment Equity Unit in the Department of Labour. However, progress is inevitably slow even in the public sector, and many indicators, such as the low representation of women in areas varying from the modern apprenticeship scheme to Directorships of Stock Exchange listed companies, show how far there is to go. Meanwhile carers and cleaners, where Maori and Pacific women predominate, still fight for a living wage. This paper examines and evaluates developments in the last two years, a period when gender and ethnic mainstreaming holds considerable sway in government. This can lead to a lack of commitment, prioritising, and accountability for results, so such monitoring from outside is essential.
\end{abstract}

\section{Introduction}

This paper examines and evaluates developments in pay equity and equal employment opportunity in the last two years. It focuses mainly on gender issues but also touches on other dimensions of equal employment opportunity (EEO), including age, disability and ethnicity.

\section{The Pay and Employment Equity Unit}

The establishment of the Pay and Employment Equity Unit in the Department of Labour (DOL), in accordance with recommendations from the 2004 Taskforce on Pay \& Employment Equity in the Public Service, Public Education and Public Health, has been an important development. However, its work covers only about $10 \%$ of the labour force and any flow on to the private sector is likely to be slow. The Unit's initial work covers development of tools and guidelines, together with training for: pay and employment equity reviews (to be followed by response plans), job evaluation, and pay investigations.

\section{Pay and Employment Equity Reviews}

The Unit assisted with two pilot reviews in 2005, at the National Library and the Auckland University of Technology, and has developed a Review Workbook (New Zealand Department of Labour, 2006). It also provides training on the tools and processes for review committees and project managers and is developing case studies to assist participants. The report on the pilot concluded that the review tool was robust and full reviews have followed. Seven Public Service organisations started their reviews within the eight months to August 2006, further thirteen were in active preparation, and some are now completed. The Director of the Unit states that "the core of the approach adopted is that sustainable change depends on active engagement in partnerships of employers, employees and unions in workplaces in identifying equity issues and agreeing on response plans to address them" (Hall, 2006).

The Unit's factsheet $2^{1}$ states that a pay review assists organisations to find out if women and men have an equitable share of rewards, women and men participate equitably in all areas of organisations, and treated with respect and fairness.

The workbook will assist review committees in gathering evidence on the impact and results of organisational policies and practices. These need to be equitable for women and men, but not necessarily the same. While the focus of the review is on gender, the process can also be used to consider other characteristics, such as ethnicity, age or disability. The final step is developing a response plan to address the employment and pay equity issues identified as priorities.

In explaining the equality/equity concepts, the workbook states: "The distinction between equality and equity is important to bear in mind. While equality refers to being equal or the same, equity refers to being just, fair or impartial. In the employment equity context, equity refers to proportionality between differences in relevant characteristics of people and jobs and how they are treated" (New Zealand Department of Labour, 2006: 10). Further, "any gender difference in the distribution of organisational rewards, participation levels and 
experience of respect and fairness should be explainable and justifiable" (ibid). But this is quickly followed by the equal pay definition of the 1960 Public Sector Equal Pay Act (similar to that in the 1972 Act covering the private sector) which has been interpreted in the courts as requiring equal pay for only identical or highly similar work, not work of equal value.

The theoretical and practical meaning of most of this terminology is highly contestable. Equality and equity. proportionality with respect to differences in characteristics and resulting treatment, and what constitutes explainable and even more so justifiable differences in treatment are the stuff of argument, not a science. The proof of the pudding will be in the eating. It is too early to assess results, and whether they will challenge the historical undervaluation of female dominated work is an open question. The review may be better able to deal with clear EEO matters than with equal value issues.

\section{Pal Investigations and Remedial Pan Settlements}

Pay investigations may be conducted using the genderneutral job evaluation tool. They are intended to provide a systematic and rigorous process for evaluating jobs in setting remuneration and may be recommended in a review response plan or initiated by employers or through bargaining. They will focus on factors affecting job size. including skills, knowledge and qualifications, as well as conditions, and also cover other factors affecting remuneration, including market influences, performance payments, and other employment conditions.

If. in spite of the issues discussed above. systemic undervaluation of female dominated work is revealed by pay reviews and or pay investigations, a key issue is how this would be remedied and finaneed. Here the role of government as employer, directly or indirectly as funder through contracts, becomes crucial and nervousness over cost can be detected. Factsheet 2 states that "the employer(s) and union(s) can negotiate the solutions through collective bargaining... The Government has decided that claims for additional funding for remedial pay settlements arising from pay and employment equity reviews will be considered within existing Budget processes, advised by a tripartite process. Claims need to be supported by a business case establishing clear evidence that there is pay inequity (preferably based on a rigorous pay investigation), whether organisations can fund the claim through re-prioritisation and how relativities based claims will be managed."

Government is clearly concerned with the possibility of extra public sector expenditure. A remedial settlement 'preferably' requires a pay investigation not just a review (and so is confined to $70^{\circ}$ or more female work), and the section provides warnings and incentives to strengthen employer resistance. Strong union expertise and commitment, matched by that of the relevant groups of employees, will be necessary if evidence is to be converted to action and a real remedy. No organization has yet reached that stage. The bipartite approach seen as essential by the Unit is dependent not only on union expertise but also on the commitment of organisations to union involvement, which will almost inevitably be variable.

A useful case study is that of librarians. Mary-Jane Gleeson, an Australian expert on pay and employment equity with experience in its applications to librarianship, visited New Zealand in 2005 to assist the Unit and participants in pilot and subsequent reviews. She was earlier involved in the New South Wales Library case which resulted in a $16 \%$ average pay increase for public sector librarians, a heavily female job category in both countries. This arose from re-assessment and documentation of the skills being applied in different jobs. Observing that women tend to use plain English language which undervalues their work, she noted that this had led to oversimplification of complex skills involved in librarian jobs.

The National Library pilot audit report, signed by management and union representatives, stated that it was intended to develop a comprehensive picture of the Library's gender profile and to focus attention and resources on areas with the most impact in bringing about pay and employment equity for women. It found a gender earnings gap of $11 \%$, but noted particularly that Librarians, a female dominated group, earned $24 \%$ less than Digital Innovation Technology Services staff, the only male dominated occupational group in the workplace, despite equivalent Job Evaluation points. It also concluded that the current Job Evaluation system was outdated. not accurately measuring all current functions, reinforced by inadequate role descriptions. Hence it argued the need for a sector wide occupational audit, with the undervaluing of librarian occupations tested and found to have substance. A concern expressed was that the audit did not have the capacity to address the issuc of pay and employment equity for librarians as an occupational group. Hence the Library's ability to influence gender equity for librarians would continue to be constrained. This reinforces the issues raised above.

\section{Joh Evaluation}

The Gender Neutral Job Evaluation tool is of course not the first attempt at such an exercise in New Zealand. The Equity at Work job evaluation scheme (Burns and Coleman, 1991) was developed under the auspices of the Employment Equity Commission and completed after its abolition. That Commission was established under the Employment Equity Act passed and repealed in 1990. A generic scheme, it was designed to be gender neutral and adaptable to specific needs. The new scheme (to be renamed Equitable Job Evaluation) has been developed and tested in conjunction with Mercer and Top Drawer consultancies. National's Industrial Relations spokesman Wayne Mapp labelled the payment of $\$ 121,000$ to these two firms for work on the scheme a wasteful and irresponsible use of taxpayers ' money', (Dominion Post, 26 June, 2006), and argued that the PEEU should have done the work itself. Department of Labour Chief Executive James Buwalda defended the expenditure on the basis of the small size of the unit and the need to draw on expertise in particular areas, given the concern to 
eliminate gender bias, an emphasis not common in job evaluation. The criticism of such a small expenditure by comparison with high consultancy fees paid by all governments in a wide range of areas might be seen as provocative and perhaps inspired by the gender emphasis of the work.

The scheme is at its final stage of development after undergoing three tests. The final test on jobs at the Ministry of Social Development is comparing the rank order with that produced by existing systems. The factor plan and guide (including questionnaire and evaluation record) are being prepared for publication, while an education and training kit is being jointly developed with the New Zealand Council of Trade Unions and the State Services Commission.

Another initiative under way on job evaluation is development of a Gender Inclusive Job Evaluation Standard, to assist in identifying and addressing gender bias. Standards New Zealand released a draft for public comment and is currently considering the submissions The process has involved input from business, unions, job evaluation providers, the Human Resources Institute of New Zealand and gender equity experts. Given extensive critiques of most standard job evaluation systems for containing gender biases (for example Burton, 1988; Hyman, 1988) this Standard is needed. It has the potential for the work of the Unit to extend beyond the $10 \%$ of the workforce covered by its core responsibilities.

\section{Contestable Fund}

This fund makes grants to organisations involved in implementing the Action Plan. It was oversubscribed in the 2006 funding round, with twenty applicants applying for a total of $\$ 2.9 \mathrm{~m}$ - $\$ 1 \mathrm{~m}$ was available. Among the criteria used were partial not full reimbursement, value for money and substantial expected gains toward implementing pay and employment equity, and funding only for new work on the review process. Successful applicants included 10 Government departments as well as public health organizations (five District Health Boards involved in reviews). With such a high proportion of funding going to government departments to appoint project managers for the audit process, it seems appropriate to ask whether a commitment to equity would indicate that such staff should be paid from core departmental funding.

Union participation in the reviews also received funding. The New Zealand Nurses Organisation is engaging members, delegates and staff at all levels in the Plan of Action. The Public Service Association has appointed a pay and employment equity advisor and its funding will help build capacity in the area for all three sectors.

Independent of the Taskforce report and subsequent work of the Unit, some trade unions have continued to use equal value arguments in their pay claims. While there is no legislation requiring anything stronger than equal pay for equal (effectively identical) work, such claims in collective bargaining have had some success. The pay settlement for public hospital registered nurses in 2005, in which equal value arguments were a strong part of the union case, has been the most important example of this type. However, it has not been comprehensively passed on to other workplaces employing such nurses, many of which are therefore experiencing staff shortages and dissatisfaction. And related female dominated caring work requiring lower qualifications, but where the skills involved are still clearly undervalued, is a major problem area (Burns et al. 1999).

\section{Equal Employment Opportunity - Public Sector}

The State Sector Act, 1988, requires Public Service CEOs to operate as 'good employers' which inter alia involves a proactive Equal Employment Opportunities programme, covering at a minimum: Maori; women; ethnic minority groups; and persons with disabilities. However, the Taskforce considered that "stronger mechanisms are required to ensure that the issues are not only identified, but also acted upon" (Taskforce, 2004: 74) which the process discussed above is intended to fulfill, at least with respect to gender. In the meantime, the State Services Commission publishes an annual EEO Progress Report for the Public Service, which tends to be thorough on statistics but cautious with respect to analysis and recommendations. The 2005 report, reviewing progress from 2000 to 2004, referred to positive trends including increased representation of Pacific peoples and Asians in the Public Service, increased representation of all the EEO groups in the managerial occupation group, and improved representation of women in senior management. It also correctly noted areas of concern, including pay gaps and low representation in senior management for several of the EEO groups. There was little change to the pay gap between female and male public servants (State Services Commission, 2005).

Universities are an interesting case study, since they strongly defend their commitment in theory and practice to merit criteria for appointments and promotion, and since most had EEO programmes and policies at an early stage, although as in the public sector, specific staffing has been reduced. However, senior academic staff are still highly male dominated, with only $16.9 \%$ of Associate Professors and Professors being women in 2005, up marginally from $15.8 \%$ in 2003 (Human Rights Commission and New Zealand Centre for Women \& Leadership, 2006). The lowest proportion is $6.3 \%$ at Canterbury University, where a case was taken in 2004 to the Human Rights Commission by Sue Newberry over her non promotion to Associate Professor. Canterbury's response defended the university's promotion procedures and argued that there was no sex discrimination involved in this case or in general. Sue Newberry has been lost to New Zealand, having obtained her Associate Professor position at Sydney University. The HRC Director of Proceedings had advised her of the potential difficulties in proving the alleged discrimination. While she could point to a series of disingenuous and illogical events, it was much more difficult to show that the primary operating factor was gender discrimination. As so often, 
the standard of proof required makes establishing gender discrimination, direct or indirect, very difficult.

Nevertheless, after 30 years or more of documentation of the issues, suspicion of subtle gender bias remains strong. A 2004 report on gender and academic promotions at Massey, surveying 619 staff members, showed that perceptions of barriers to promotion and lack of feedback on failure still remained more common among women. Massey academic women were five times more likely than men to believe that having time away from the workforce is a barrier to promotion, and three times as likely to mention the lack of affordable childcare. Women were only half as likely as men to feel they had reached the academic level to which they aspired. More women than men identified barriers to promotion such as high teaching loads and a lack of time for research (Doyle et al. 2004). Canterbury's Pro Vice Chancellor acknowledged in response to the report that there might be at all our universities a lack of parity with regard to gender that can be extremely subtle.

\section{Equal Employment Opportunity - Private Sector}

In the private sector there are many indicators showing that there is a long way to go to achieve gender equality. The Modern Apprenticeship scheme is mainly a male domain with the female proportion having increased only from $6.6^{\circ}$ o in 2003 to $8.5^{\circ}$ in March 2006. Women were over one third of participants in tourism, public sector, retail, hospitality and seafood, but a miniscule proportion in the male traditional areas $(10$ out of 1430 in engineering and 6 out of 1315 in building and construction. the two largest groups overall). Clearly thirty years of work to encourage women into these trades has had little impact. To increase female participation, the scheme has incorporated industries that are more traditionally 'female' - such as retail - but which still tend to be lower-paid and with less developed career paths than the traditionally 'male' skilled trades. The EEO Commissioner Judy McGregor warns that this approach to gender-balancing the scheme reinforces stereotypes, and will not see more women in high-skill, high-paid technical jobs, perpetuating occupational segregation.

At the other end of the spectrum is the underrepresentation of women in private sector boardrooms. The top 100 firms on the New Zealand Stock Exchange still had only $7^{\circ} \%$ women directors in 2006. up from $5^{\circ}$ o in 2003. (Human Rights Commission and New Zealand Centre for Women \& Leadership. 2006).

The only legislative underpinnings for EEO in the private sector are the anti discrimination provisions of industrial relations and human rights law. Despite the difficulties outlined above in establishing discrimination on specific grounds (gender, ethnicity, age etc) to the standard of proof required, there has been one recent suceess in the Talley ease. Caitlin Lewis claimed that Talley's discriminated against women by not giving them a chance to do higher-paid work and this was upheld by the Human Rights Review Tribunal. Talley's hiring process was described by the Office of Human Rights Proceedings as 'a drafting gate', with men automatically steered into higher-paid fish filleting jobs and women into lower-paid trimming jobs. Its Director, Robert Hesketh, said that the case "establishes quite clearly that [Talley's] was practising sex-discrimination in the way it allocated its roles and that the decision is going to require larger employers with a varying workforce and varying tasks, to audit what they do and make sure that any divisions along sex lines are for sound reasons, not for historical reasons that aren 't relevant. One of the reasons that Talley's gave for preferring men in the [higher paid] filleting role was that it involved lifting heavy containers of fish. The lie that you can put to that, was that the woman plaintiff in the Talley's case was a six-foot, strongly built woman who would have had no difficulty whatsoever, as she put it, "huffing 'bins of fish" (http://www.neon.org.nz /newsarchive/talleydiscrimination/).

Good EEO information and resources are available on the web, with the development by the Human Rights Commission and the Equal Employment Opportunities Trust of the National Equal Opportunities Network (NEON) site quoted above. NEON's resources include profiles of EEO groups, information about EEO issues, advice for Crown entities on being a 'good employer', national and overseas news, and research and case studies, as well as links to others working in EEO. The Trust's own site http://www.eeotrust.org.nz/ is also a useful resource.

Various minimum code provisions, such as the minimum wage and parental leave, together with some government programmes, such as provision and subsidies for child care, and policies, for example on breastfeeding in the workplace, also have EEO impacts. Those which particularly affect parents with dependent children have major gender impacts in practice, since women continue to take the major role in family related responsibilities. Hence the extension of paid parental leave to 14 weeks and the inclusion of self employed parents are positive developments, although further improvements to eligibility, particularly for casual and seasonal workers, and to the length of leave and level of payment are desirable. On breastfeeding, the Human Rights Commission has recommended the provision of a legal framework for the right to breastfeed at work but this has not been taken up.

\section{Age, Disability and Ethnicity}

Age discrimination (against both the youngest and oldest in the labour foree) is another issue rightly receiving increasing attention. There is a substantial irony with respeet to the position of older workers. On the one hand, labour force participation among this group has been increasing quite rapidly, pulled by greater longevity, improved average health levels, and the wish by some, including women who have had periods out of the labour force, to remain in paid work longer for financial and other reasons. It has also been pushed by the increase to 65 for eligibility for New Zealand Superannuation (NZS) 
and by fears that this may rise further with population ageing and concern over the rising proportion of the government budget taken by NZS. Yet, despite human rights legislation making discrimination on the basis of age unlawful, there is evidence of substantial prejudice against older workers by employers. Clearly higher employment levels are good for the economy, given labour shortages. We need to use all our human capital, particularly the experience and skills among this group.

The EEO Trust's Work and Age Survey explored what 6,484 respondents want from work as they get older and what would encourage them to continue to contribute their skills and experience at work. For most working people, the ideal transition from full-time work to retirement would involve part-time work or more flexible working hours. About one in three respondents said they had experienced discrimination at work due to their age (EEO Trust, 2006). A recent study of barriers to entry for the older worker used a field experiment (written applications and resumes to apply for 75 advertised positions), a short listing simulation, and interviews with employers and recruiters. "Younger workers were seen as more suitable and were significantly more likely to be short-listed." For example "for low demand (HR administrative) positions, the resume of a $25+$ year old worker was six to twelve times as likely to be short-listed as the equivalent resume of a 55+ worker" (Wilson and Kan, 2006: 2).

An EEO Trust on-line survey of disability and employment with 368 responses highlighted the achievements, commitment and talents of disabled people. Despite high awareness of their strengths and skills, many respondents had found it hard to get a job and had come up against barriers that prevented them from making the contribution they were capable of at work (EEO Trust, 2005)

On ethnicity, statistical indicators show ongoing disadvantage in the labour market for Maori and Pacific people. A recent study of the settlement experiences of immigrants and refugees in New Zealand documents a growing literature in the area, in which "regrettably, the experience of discrimination, exclusion and prejudice figures prominently" (Butcher, Spoonley and Trlin, 2006: v). In focus group discussions, "participants noted that the discrimination they experienced was subtle, rather than overt and explicit" but nevertheless strong. Employment was a major focus with repercussions in other areas. Significant issues in acquiring employment and on the job included: "the recognition of overseas qualifications; the desirability of New Zealand qualifications and work experience; application procedures; the sense of being an outsider; and language and accent" (ibid: vi).

Flexibility in employment is an important issue not only for older workers, but also for other groups, especially those with significant family responsibilities. Creating family friendly workplaces and assisting individuals to secure a satisfactory work life balance is now a common mantra, although there has probably been more talk than action. The latest substantive move is the introduction by Green MP Sue Kedgley of a private members bill guaranteeing a right to request flexible working hours by parents with young or disabled children. It is based on similar 2003 UK legislation with many applications made and $90 \%$ of them agreed to by employers. A Coalition for Quality Flexible Work is calling for the provisions to be extended to all employees, pointing to research showing considerable benefits for employers who introduce flexible working hours in staff recruitment and retention as well as increased productivity. While requests rather than major obligations are imposed by this approach, the change in climate could make a real difference.

\section{Other Legislative and Policy Initiatives with Potential Impacts on Pay and Employment Equity - Low Paid Work and Union Action}

Realism dictates acknowledgement of the problems of achieving satisfactory outcomes from specific gender and ethnic anti discrimination and equality policies discussed above despite their symbolic importance. In most circumstances the general economic and industrial relations environment and legislation have greater impact on pay and employment equity than more direct approaches. The level of the minimum wage thus has an important role in protecting lower waged workers, particularly when collective bargaining is weak. The CTU estimates that of the 91,000 workers for whom the latest minimum wage boost directly led to a pay rise, 61,000 were women. The relativity of minimum to average wages has fluctuated widely over the years in New Zealand with extremes of 83 percent initially (in 1947) and 30 percent in 1984 (Hyman, 2004). Minimum rates have been raised more since 1999 under Labour led governments than in previous years but this has only partially restored relativities to a current rate of about $50 \%$ with the hourly rate raised to $\$ 10.25$ in March 2006 and the youth rate for $16 / 17$ year olds maintained at $80 \%$ of the adult rate or $\$ 8.20$ per hour.

Unions are campaigning for a higher minimum wage, and for the abolition of the lower youth wage, in addition to general wage increases and improvements in specific industries, especially the lowest paid areas. Strike action has been used more than in recent years in both professional (e.g. junior doctors) and blue collar areas. The CTU is calling for the minimum wage to be set at two thirds of the average wage, and then indexed at this level. They also call for an immediate increase to $\$ 12$, rather than in 2008, which the Labour led government is aiming for if the economy, in their view, permits this. A Workers Charter launched in 2005 has a list of ten demands aimed at guaranteeing workers' rights, while its associated monthly newspaper, launched in February 2006, is a resource for the campaigns. It has called for a minimum wage as high as $\$ 15$ per hour. With average hourly earnings in June 2006 about $\$ 20$, the $\$ 12$ target would mean a $60 \%$ relativity, while a $2 / 3$ ratio would require $\$ 13.33$ per hour.

A private member's bill to end youth rates, the Minimum Wage (Abolition of Age Discrimination) Amendment Bill, sponsored by Sue Bradford, is before the Transport and Industrial Relations Committee. Labour supported its first reading, but has not yet released a final position. Its 
proponents argue that there is no sensible argument for youth rates - equal pay for equal work should apply as much to age as gender and ethnicity.

The tight labour market is among the reasons why workers and unions are able to reassert some muscle after a comparatively quiet period. Victoria University of Wellington's survey of union membership shows an increase of 23.290 union members or $6.6 \%$ in 2005 , taking the total to 377,348 and union density to its highest level since 1998, at $21.9 \%$.

The campaigns for general wage increases and improvements in low paid industries include the Fair Share campaign, launched in 2005 to fight for a general $5 \%$ wage increase. Supersizemypay.com, and campaigns in cleaning, aged care, fast food and retail. The campaigns gained momentum with strong support among and for supermarket warehouse employees locked out by Progressive Enterprises, owned by Australian retailing giant Woolworths when seeking national pay parity. The eventual three-year settlement achieved the union aim of equal pay across Auckland, Palmerston North, and Christchurch distribution centres. While not achieving one national agreement, the three documents were based on national bargaining. The unions hailed a victory. claiming major public support and strong solidarity.

The Clean Start - Fair Deal for Cleaners campaign of the Service and Food Workers' Union (SFWU) has called on the government to look closely at the inequalities suffered by Pacific Island and Mãori workers employed as cleaners in Auckland and Wellington CBD office blocks. The Fair Share for Aged Care campaign of the New Zealand Nurses Organisation and SFWU aims for increased government funding for the sector, targeted to fair pay for the predominantly female caregivers, nurses and support workers, safe staffing levels, better training opportunities, and recognition of training in improved pay. Noting that profits have soared for Aged Care operators. now almost all controlled by multi-national corporations, unions and employees are concerned with what they see as the employers consistent refusal to passon a fair share of huge annual profits. The work of caregivers is intensified with greater elderly dependence but wages have scarcely increased for many years with $\$ 12$ per hour common in this female undervalued occupation.

Another union campaign has focused on defeating the Employment Relations (Probationary Employment) Amendment Bill (the National sponsored Mapp Bill') which would introduce a 90-day probation period for new employees. Its purpose was stated to be to enable employers to take a chance with new employees, without facing the risk of expensive and protracted personal grievance procedures. Proponents argued that it would enable people who have not had previous work experience to find their first job and make it easier for people re-entering the workforee. The Bill, eurrently before a select committec, would mean no right of appeal against unfair dismissal in the first 90 days. Union critics argue that it is creates a category of 'disposable worker'. The Māori party has now come out against the Bill, to the relief of the CTU Rūnanga which argued that it would do nothing to solve Māori unemployment, exposing Māori workers to unfair dismissal, rather than investing in them.

\section{Conclusion}

In a world economy where dominant transnational corporations can locate and outsource in pursuit of minimum employment costs, it is hardly surprising that New Zealand governments and business place emphasis on labour market flexibility, minimising compliance costs, and avoiding new legislative regulations. In this environment, any stated commitment to gender and ethnic equality is likely to have little teeth. Gender and ethnic mainstreaming limits prioritisation and accountability. Achievements by women are often portrayed as being at the expense of men and special provisions to lift the position of Māori and other ethnic groups or women regarded with suspicion. Reductions in gender and ethnic inequality in educational and other human capital acquisition have nevertheless occurred and will continue given social change, pressure from the groups previously denied equal access, and the economic imperatives to use all our labour resources fully. However, some groups are slow to benefit. Equal opportunity is therefore far from a reality, while the undervaluation of many types of female dominated work can only be remedied by requiring systematic processes throughout the labour market. Research and monitoring remains essential.

\section{Future Research}

Continued monitoring is essential if legislative and policy commitments are to be honoured and improved and to avoid any erosion of past gains on the basis that all that is necessary has already been done. It is to be hoped that confidentiality does not prevent the experience of organisations undertaking public sector, health and education pay reviews or using equitable job evaluation being built on - wide dissemination of the planned case studies and research on the efficacy and possible use elsewhere of the review process is highly desirable.

\section{Note}

I Factsheet 2 can be found at:

http:/www.dol.govt.nz/services/PayAndEmploym entEquity/factsheets/fs2-plan.asps

\section{References}

Burns, J. and Coleman, M. (1991). Equity at Work - An Approach to Gender Neutral Job Evaluation. Wellington: State Services Commission and Department of Labour.

Burns, J., Dwyer, M., Lambie, H. and Lynch, J. (1999). Homecare Workers: A Case Study of a Female Occupation. Wellington: Ministry of Women's Affairs. 
Burton, C. (1988), Redefining Merit. Canberra: Affirmative Action Agency Commonwealth of Australia, Monograph No 2.

Butcher, A., Spoonley, P. and Trlin, A. (2006). Being Accepted: The Experience of Discrimination and Social Exclusion by Immigrants and Refugees in New Zealand. Palmerston North: New Settlers Programme, Massey University, Occasional Publication No. 13.

Doyle, S., Wylie, C. and Hodgen, E. with Else, A. (2004). Gender and Academic Promotion: A Case Study of Massey University. Wellington: New Zealand Council for Educational Research.

EEO Trust. (2006). Work and Age Survey Report. Auckland: EEO Trust.

EEO Trust. (2005). Disability and Employment - Online Survey Analysis. Auckland: EEO Trust.

Hall, P. (2006). New Zealand's proactive pay and employment equity plan of action. Paper to International Association for Feminist Economics Conference, Sydney.

Human Rights Commission and New Zealand Centre for Women \& Leadership, Massey University. (2006). New Zealand Census of Women's Participation.

Hyman, P. (1988). Equal pay for work of equal value job evaluation issues. New Zealand Journal of Industrial Relations, 13(3), 237-255.

Hyman, P. (2004). Significant increases in the minimum wage: A strategy for gender pay equity? Women's Studies Journal, 18(2), 11-24.
Hyman, P. (2006). Pay equity and equal employment opportunity: Policy, rhetoric and reality in the 2004 New Zealand labour market. In Blumenfeld, S.B. and Lafferty, G. (eds) (2006). Proceedings of Eleventh Conference on Labour, Employment and Work, Wellington: Victoria University of Wellington, 283-288.

New Zealand Department of Labour. (2006). Working Towards Pay and Employment Equity for Women in Public Health, Public Education and Public Service, Wellington: Department of Labour.

State Services Commission. (2005). EEO Progress in the Public Service 2000 - 2004: The Data Stories. Wellington: State Services Commission.

Taskforce on Pay and Employment Equity. (2004). Report on Pay and Employment Equity in the Public Service and the Public Health and Public Education Sectors. Wellington. Taskforce on Pay and Employment Equity.

Wilson, M. and Kan, J. (2006). Barriers to Entry for the Older Worker. Auckland: University of Auckland Business School.

\section{Author}

Prue Hyman

Research Associate

Gender and Women's Studies

Victoria University of Wellington

P.O. Box 600

Wellington

Prue.Hyman@vuw.ac.nz 